\title{
DIEZ AÑOS DE POLÍTICA MIGRATORIA: AVANZANDO HACIA LA RESPONSABILIDAD
}

\author{
Gloria Inés Ospina ${ }^{1}$ \\ UNISCI
}

\begin{abstract}
Resumen:
Durante la última década, los gobiernos españoles han ido aprendiendo de la inmigración una lección simple, como es que los estados no deben ir a remolque de la pauta marcada por los flujos migratorios. Diez años en los que las políticas migratorias han pasado de ser fundamentalmente securitarias a integradoras, aunque en los últimos cuatro años se han ido convirtiendo en políticas migratorias más controladoras y persecutorias que nunca. España, en estos 10 últimos años ha tenido, a nuestro juicio, una política migratoria con una línea de continuidad, marcada por el control de la inmigración y la persecución a la inmigración ilegal, como una clara divisa de su pertenencia al espacio europeo Schengen.
\end{abstract}

Palabras clave: Inmigración, flujos migratorios, securitarias, control, persecución, Schengen.

Title in English: “The Years of Migratory Policy: Moving on towards Responsibility”.

\begin{abstract}
:
During the last decade, Spanish governments have been learning a simple lesson from immigration: States must not go behind the migration flows guideline. In these ten years, migration policies have changed from being basically securitarian to being inclusive, despite in the last four years they have been reconverting to the most controlling and persecutory migration policies ever. In our opinion, Spain has had a continual migration policy in the last 10 years, marked by the immigration control and the persecution of the illegal immigration; this is a clear sign of its belonging to Shengen Area.
\end{abstract}

Keywords: Inmigration, migration flows, securitarian, control, persecution, Schengen.

Copyright (C) UNISCI, 2011.

Las opiniones expresadas en estos artículos son propias de sus autores, y no reflejan necesariamente la opinión de UNISCI. The views expressed in these articles are those of the authors, and do not necessarily reflect the views of UNISCI.

\footnotetext{
${ }^{1}$ Gloria Inés Ospina Sánchez es Historiadora y Geógrafa de la Población, Investigadora UNISCI, SECCIÓN Inmigración. Dirección: Facultad de CC. Políticas. Dpto. de Relaciones Internacionales. Universidad Complutense de Madrid. Campus de Somosaguas. 28223 Madrid, España. E-mail: ginesos@ @otmail.com. http://dx.doi.org/10.5209/rev_UNIS.2011.v27.38153
} 


\section{Introducción}

Durante la última década, los gobiernos españoles han ido aprendiendo de la inmigración una lección simple, como es que los estados no deben ir a remolque de la pauta marcada por los flujos migratorios.

Diez años en los que las políticas migratorias han pasado de ser fundamentalmente securitarias a integradoras, aunque en los últimos cuatro años se han ido convirtiendo en políticas migratorias más controladoras y persecutorias que nunca.

Desde la ley de extranjería que promulgó el partido Popular, que fue rechazada por importantes colectivos especializados en inmigración, hasta el reglamento actual que pone en funcionamiento la ley de extranjería, aprobada en 2009, el acento se pone en el control y en "la descalificación del inmigrante ilegal". Ley de extranjería que, por cierto, ha sido consensuada y "dado el visto bueno" por los sindicatos de izquierda.

Como lo estipula claramente el reglamento de 30 de abril último, cuando se refiere a la necesidad de crear una "cultura de la legalidad" dentro del colectivo inmigrante, sea éste legal o ilegal.

La ley de extranjería de diciembre de 2009, tiene en cuenta las normativas europeas que afectan al derecho de extranjería de los estados que integran la UE, de forma que esta ley es una forma de ajuste jurídico con las normas que se aprueban en la UE.

Entre las normativas, destaca por su importancia, la firma del Pacto Europeo sobre Inmigración y Asilo, refrendado en el Consejo Europeo, el 16 de octubre de 2008, por los 27 países de la UE, en el cual se establecen como principales objetivos conseguir una inmigración legal y ordenada, luchar contra la inmigración ilegal y favorecer la integración de los inmigrantes legales, mediante un equilibrio entre derechos y deberes.

En el texto se insiste en lo positivo de la reforma y la necesidad de contar con un marco normativo europeo común en materia de inmigración.

A este respecto se tuvieron en cuenta para la redacción del nuevo texto todas las normativas que desde el año 2003 al 2008, fueron aprobadas en el Consejo y el Parlamento de la UE y que regulaban aspectos tan dispares como, por ejemplo, La asistencia en casos de tránsito a efectos de repatriación o alejamiento por vía aérea. (Directiva 2003/110/CE, del Consejo, de 25 de noviembre de 2003. (DOUE de 6 de diciembre de 2003); la obligación de los transportistas de comunicar los datos de las personas transportadas. (Directiva 2004/82/CE, del Consejo, de 29 de abril de 2004, DOUE de 6 de agosto de 2004); las normas y procedimientos en los Estados miembros para el retorno de los nacionales de terceros países en situación ilegal. (Directiva 2008/115/CEE, de 16 de diciembre de 2008, del Parlamento Europeo y el Consejo. DOUE de 24 de diciembre de 2008), entre otras.

Me parece conveniente echar la vista atrás y recordar aquel denominado Plan GRECO, o Programa Global de Regulación y Coordinación de la Extranjería y la Inmigración en España, que fue diseñado por el gobierno del presidente Aznar, para el período 2001-2004. Plan que coordinaba la "regulación de la inmigración y la integración de los inmigrantes residentes y legales”, así como el mantenimiento del sistema de protección de refugiados y desplazados en nuestro país. 
Iniciativa que se enmarcaba dentro de las directrices europeas, estructurándose en base a cuatro líneas de desarrollo plurianual y de coordinación con todas las administraciones y agentes sociales, aunque, a decir verdad, el peso específico lo tenía fundamentalmente el ministerio del Interior, más concretamente el departamento de Inmigración.

Las líneas de desarrollo eran:

-Desafío global y coordinado de la inmigración como fenómeno deseable para España en el marco de la UE.

-Integración de los residentes extranjeros y sus familias que contribuyen activamente al crecimiento de nuestro país.

-Regulación de los flujos migratorios para garantizar la convivencia en la sociedad española.

-Mantenimiento del sistema de protección para los refugiados y desplazados.

En opinión del secretario de Estado de Extranjería, Enrique Fernández-Miranda, se trataba con este programa de "convertir el círculo vicioso de la inmigración ilegal, en un círculo virtuoso", para facilitar la integración social y legal en la sociedad española. Se hablaba también en esos años, de programa para la convivencia multicultural.

Programa que fue duramente criticado por la secretaria de Políticas Sociales e Inmigración del PSOE, Consuelo Rumí, alegando que el plan GRECO carecía de contenido y se limitaba a simples enunciados.

Precisamente, con el cambio de gobierno en 2004, Consuelo Rumí fue nombrada Secretaria de Estado de Inmigración, que pasaría a depender del ministerio de Trabajo y Asuntos Sociales. ${ }^{2}$

En esta nueva etapa se presentaba "una cara amable" a la inmigración, que ahora dependía del ministerio de Trabajo y Asuntos Sociales, y fue durante su gestión cuando se realizó una de las más controvertidas regularizaciones, que en opinión de los responsables europeos, tendría consecuencias inesperadas. Regularización de inmigrantes que el gobierno del presidente Rodríguez Zapatero llevó a cabo en el año 2005, y que más tarde fue defendida por Consuelo Rumí, "por la cantidad de inmigrantes trabajando en la economía sumergida, que en su opinión era la herencia de la mala gestión del partido Popular". 3

Más adelante, en el año 2009, Consuelo Rumí, refiriéndose a la aprobación de la Ley de Extranjería", comentaba que: "no se contemplaba ningún proceso de regulación de inmigrantes ilegales", afirmando que era una ley que cumplía con el Pacto de Inmigración de la UE, pacto que ella misma recordó, fue promovido por los gobiernos de España, Francia y

\footnotetext{
${ }^{2}$ Consuelo Rumí fue considerada persona de confianza del presidente José Luís Rodríguez Zapatero ya en la etapa en que fue nombrado Secretario General del PSOE, quien la nombró, a su vez, Secretaria de Ocupación, Políticas e Inmigracíón del partido.

${ }^{3}$ Curso de Verano, Universidad Juan Carlos I. Aranjuez, julio de 2007. Véase en http://www.migrantesecuador.org/content/view/191/253

${ }^{4}$ Ley Orgánica 2/2009, de 11 de diciembre, de reforma de la Ley Orgánica 4/2000 de 11 de enero, sobre derechos y libertades de los extranjeros en España y su integración social. Boletín Oficial del Estado, n 299 (12 de diciembre de 2009).
} 
Alemania. Comentario que deja clara la diferencia que existe entre pertenecer a la oposición o formar parte del gobierno de la nación. ${ }^{5}$

Prácticamente, se defendía lo mismo que defendía el partido Popular en el año 2001: una política migratoria que trabaja en la lucha contra la inmigración clandestina, la ordenación de los flujos migratorios y la integración de los inmigrantes, pero con un lenguaje "menos directo" y un programa de asistencia primaria dirigido a la inmigración "sin papeles".

Desde 2001 al 2011, las políticas referentes a la inmigración han seguido un hilo conductor que ha sido marcado por la UE y también por los gobiernos de países que como España, Francia, Italia o Grecia son frontera exterior del espacio Schengen y se han visto "amenazados" por oleadas de flujos migratorios, como nunca se había experimentado en Europa, especialmente en los casos español, italiano y griego.

En lo que se refiere a España, en estos diez años de políticas migratorias, ocho corresponden al gobierno socialista, del presidente Rodríguez Zapatero, cuya principal preocupación en relación con la inmigración fue la integración laboral, considerada como el primer paso para la integración social satisfactoria. Otra de las cuestiones que pretendió atajar fue la de los flujos migratorios ilegales.

El gobierno, con su discurso "cercano a la inmigración" había puesto en marcha varias acciones políticas para fomentar la integración. Una fue el Plan Estratégico de Ciudadanía e Integración elaborado con la colaboración de Ayuntamientos, Comunidades Autónomas, ONGs y expertos, cuyo presupuesto fue de 2.000 millones de euros. Otro fue el Fondo para la Acogida e Integración, creado por primera vez y financiado en 2005 con 120 millones de euros y en 2006 con 182 millones de euros. En comparación, en el año 2004, todavía gobernando el partido Popular, la financiación que se destinaba para la integración de la inmigración era de siete millones de euros.

A estos programas les siguió la aprobación del Reglamento de la Ley de Extranjería de 30 de diciembre que abrió un proceso de regularización especial de tres meses, entre el 7 de febrero y el 7 de mayo de 2005, destinado a los trabajadores irregulares, que se encontraban en España, que tuvieran un contrato por un mínimo de seis meses, llevaran al menos 6 meses viviendo en España y carecieran de antecedentes penales. Según datos del ministerio de Trabajo y Asuntos Sociales, el proceso de regularización, resolvió un total de 688.419 expedientes, de los que el 83\% (573.270) fueron autorizaciones positivas y el 16\% (115.149) denegadas y archivadas.

En principio, nunca hemos criticado esta medida, por una parte, porque la han llevado a cabo también gobiernos europeos como Alemania, en 2006, y se continúa haciendo en Alemania y Francia, con la regularización estudiada "caso por caso", en función del empleo y factores humanitarios, y por otra parte, era el reconocimiento del problema de la clandestinidad y "el limbo jurídico" en que se encontraba, situación aprovechada, tanto por la empresa privada como por la estatal y autonómica y municipal, en obras públicas. Se pretendió con esta medida, colocar el "contador" de la inmigración ilegal a cero.

En el primer semestre de 2005, de enero a agosto se interceptaron 6.361 inmigrantes que llegaron en patera, frente a los 10.042 del mismo período de 2004. Este descenso se debía en parte a la colaboración de Marruecos, que en opinión de la secretaria de Estado para la

\footnotetext{
${ }^{5}$ Véase en

http:/www.parainmigrantes.info/\%C2\%BFregularizacion-de-extranjeros-y-la-nueva-ley-de-extranjeria/.
} 
inmigración, ayudaba a controlar la inmigración ilegal hacia España. No en vano, los servicios de inteligencia españoles llevaban alertando desde hacía más de un año, sobre el creciente número de inmigrantes que se concentraban en el reino alauí. Por lo que Marruecos comenzaba a tener problemas con esta inmigración en "tránsito", a la espera de poder pasar a Melilla.

El efecto "tapón" que ejercía Marruecos, de los subsaharianos que las "redes" traían desde Nigeria, Malí, Niger, Mauritania, Argelia y Libia, era consecuencia directa del blindaje electrónico del Estrecho y Canarias, produciendo una presión humana en el "cuello de botella" de la frontera con Melilla y Ceuta, que dio lugar a episodios dramáticos con el asalto por la fuerza de decenas de inmigrantes, en el año 2005. Los sucesos de Melilla y Ceuta fueron tomados muy en serio por el gobierno español, que de inmediato reforzó la frontera con Marruecos en las dos ciudades, con efectivos pertenecientes a unidades de legionarios y regulares de las comandancias militares de las dos ciudades autónomas, que actuarían bajo el mando de la Comandancia de la Guardia Civil. ${ }^{6}$ Por su parte, el gobierno marroquí, por medio del ministro del Interior, Mustafá Sahel, anunció a su homólogo español, José Antonio Alonso, que las autoridades de Rabat procederían al refuerzo de las fuerzas de seguridad en torno a las zonas fronterizas con otros 1.600 efectivos. De ellos, un millar se habían enviado a Melilla y el resto a Ceuta.

Estas medidas disuasorias sirvieron para que la inmigración disminuyera por las costas andaluzas, que contabilizó unos 4.002 inmigrantes, mientras fue en aumento hacia el archipiélago canario, con la llegada, de enero a agosto de 2006, de unos 18.858 inmigrantes. El blindaje del Estrecho, obligó a los "sin papeles" a buscar otras rutas más al sur y más peligrosas. Comenzaron a partir desde Senegal y Mauritania, en un viaje más arriesgado, pero que daba la seguridad de llegar a España y Europa.

La vicepresidenta del gobierno, María Teresa Fernández de la Vega, en reunión con Durao Barroso, presidente de la Comisión europea y con Franco Frattini, vicepresidente, y la Comisaria de Asuntos Exteriores, Benita Ferrero-Waldener, analizaron la situación generada en Canarias por la llegada "masiva" de inmigración ilegal procedente de África subsahariana. ${ }^{7}$

España pedía ayuda ante la "avalancha de cayucos" y Europa le prometía una serie de apoyos que más estaban en consonancia con la defensa del territorio ante la amenaza de una fuerza bélica incapaz de acometer. África llamaba a las puertas del bienestar europeo.

La petición de ayuda, reforzó la idea que ya se venía proponiendo desde los Consejos de Niza y Laeken, respecto a cómo acometer el complejo tema de la inmigración, también tenido en cuenta en el Programa de Acción de la Haya, para el período 2005-2010, referente a la toma de posición de la UE por medio del Consejo y del Parlamento para ir implantando una política común de inmigración, por lo que la legislación nacional, de los 27 estados miembros de la UE,tendría que adaptarse a favor de la comunitaria. ${ }^{8}$ Programa que tenía en cuenta prioridades que incluían la lucha contra la inmigración ilegal, el retorno de los inmigrantes

\footnotetext{
${ }^{6}$ Declaraciones de la Vicepresidenta del gobierno, María Teresa Fernández de la Vega al periódico El Mundo. Véase: "Cinco muertos en un asalto en la frontera de Ceuta; Zapatero moviliza a 480 soldados", 29 de septiembre de 2005, en http://www.elmundo.es/elmundo/2005/09/29/sociedad/1127968660.html.

${ }^{7}$ Ministerio de la Presidencia, 15 Medidas urgentes de la UE contra la inmigración ilegal, Vicepresidencia Primera del Gobierno, Centro de Prensa. Miércoles 24 de mayo de 2006. Véase en: http://.mpr.es.

${ }^{8}$ Véase al respecto el estudio del equipo de Investigación UNISCI, que realizó en el año 2008, en base al trabajo de campo en diversos países africanos, así como en Canarias y en Madrid con los organismos dedicados a atender la inmigración subsahariana que entró por Canarias. Marquina, Antonio (ed.) (2008): Flujos migratorios subsaharianos hacia Canarias-Madrid, Madrid, UNISCI, pp. 352 y ss.
} 
clandestinos y la cooperación con terceros países. En diciembre de 2005, estas políticas continuaron su avance en línea con lo planteado en la Haya, habiendo presentado la Comisión un Plan de Política sobre Inmigración Legal, para el período 2006-2009, que permitiera a la UE hacer frente a los nuevos desafíos demográficos, así como a la propia gestión de los flujos migratorios.

A toda esta reglamentación comunitaria se unirían las celebraciones de cumbres y reuniones que pondrán en la escena a regiones geográficas como África en su conjunto, dando como resultado más llamativo la Conferencia euroafricana de migraciones, celebrada en julio de 2006 en Rabat y la reunión ministerial entre la UE y África, sobre migraciones y desarrollo que tuvo lugar en Lisboa en noviembre del mismo año.

En estas reuniones se sientan las bases para la acción conjunta dirigida a la lucha contra la inmigración ilegal y las causas profundas de las migraciones. Compromisos que se reforzaron en la Cumbre Europa-África-Europa, celebrada en Lisboa el 9 de diciembre de 2007, donde se consolidan los compromisos de cooperación entre los dos continentes con el fin de evitar las causas profundas de la migración.

España que no era ajena a nada de lo que se desarrollaba en Bruselas, iba activando uno de los programas que se tenían para África subsahariana, como objetivo prioritario de su política exterior, el denominado Plan África, para el período 2006-2008, que serviría para completar el control de los flujos masivos de inmigración ilegal hacia las costas españolas. Como precedente más inmediato fue la estrategia de la Unión Europea para África, adoptada en el Consejo Europeo de diciembre de 2005, iniciativa impulsada por España, como se recoge en el Enfoque global sobre migración. ${ }^{9}$

Políticas que se fortalecen durante el segundo semestre de 2008, cuando bajo la presidencia francesa de la UE, se vuelve a hacer hincapié en que "el desarrollo de una política europea global en el ámbito migratorio, seguía siendo una prioridad fundamental de la Unión. Para ello nada mejor que proponer un Pacto europeo sobre inmigración y asilo en el marco del Consejo Europeo ${ }^{10}$. Pacto destinado a sentar las bases de una política común reforzada con un espíritu de responsabilidad y solidaridad, en donde se incluían cuatro dimensiones del enfoque global de las migraciones:

-Mejor organización de la inmigración legal

-Lucha más eficaz contra la inmigración ilegal

-Fomento de una estrecha colaboración entre los países de origen, tránsito y destino de los inmigrantes.

-Mejorar los controles en las fronteras.

\footnotetext{
9 “Enfoque global sobre migración”, Notas de la Comisión Europea sobre Migraciones, Consejo Europeo de diciembre de 2005, diciembre de 2006 y diciembre de 2007, pp. 1-2.

10 "Pacto Europeo sobre Inmigración y Asilo" Síntesis de la legislación de la UE (24 de septiembre de 2008. Europa), en

http://europa.eu/legislation_summaries/justice_freedom_security/free_movement_of_persons_asylum_immigrati on/j10038_es.htm.
} 
Por último, se llama la atención a los estados miembros de la UE para que trabajen en coordinación bajo el seguimiento del Consejo Europeo, sabiendo que "en un espacio de libre circulación de personas, como es el espacio Schengen, las decisiones tomadas por unos, repercuten en los otros estados". ${ }^{11}$

Pacto que se acordó redactar con los representantes españoles que sólo se oponían a la figura del contrato de integración defendido por Francia, mientras que aseguraban que no se opondrían a rechazar las regularizaciones "arbitrarias y generales" de inmigrantes, que no se hagan caso por caso y que no tengan en cuenta el mercado laboral. Si se incluyeran esas matizaciones, el gobierno español estaría satisfecho, porque consideraba que dejaba fuera de todo reproche a la regularización que emprendió en 2005, que en sí fue una normalización, ya que se hizo "caso por caso", en base a las necesidades del mercado laboral y antes de que existiera una política común de inmigración europea. ${ }^{12}$

El primer paso para llegar a conseguir el tan deseado pacto europeo para la inmigración se había dado con la aprobación por la eurocámara de la Directiva de Retorno, el 18 de junio de 2008, promoviendo el retorno voluntario, introduce normas comunes para el retorno de inmigrantes ilegales procedentes de países no comunitarios, establece estándares mínimos para la retención temporal, con períodos máximos de internamiento e introduce un enfoque común para la prohibición de reingreso en la UE. También se dice en el texto que ..."los estados deberán legalizar a los inmigrantes o pedirles que se vayan, para lo que se dará un período de salida mínimo de 7 días". ${ }^{13}$

El paraguas de la UE ha servido al gobierno del presidente Zapatero para llevar a cabo todas las reformas que hasta el momento actual se han llevado a cabo en cuestión de inmigración. También la Directiva de Retorno fue apoyada por diputados socialistas españoles en el Parlamento europeo, mientras que en España se hacían declaraciones sosteniendo que la Directiva "no se aplicaría en España, en donde sólo se producirían algunos ajustes necesarios, pero que no significaba que hubiera un cambio de política". ${ }^{14}$

¡Y vaya si no se ha aplicado y si no ha habido un cambio de política! Gracias a su aplicación, el gobierno ha conseguido disgustar a todos los gobiernos latinoamericanos y a los africanos, aunque con estos últimos practica la política de los acuerdos de repatriación a cambio de ayudas, como lo recogen el Plan África 2006-2009 y el Plan África 2009-2012, que se han elaborado acorde con la política exterior llevada a cabo por la UE, hacia el continente africano.

\footnotetext{
11 "Una Europa que actúa para hacer frente a los desafíos actuales”. Programa de Trabajo, Presidencia francesa del Consejo de la Unión Europea (1 de julio-31 de diciembre, 2008), en http://www.eu2008.fr/webdav/site/PFUE/shared/ProgrammePFUE/Programme_ES.pdf.

12 "España y Francia siguen sin anunciar un acuerdo en torno al Pacto de Inmigración”, Europa Press, 3 de julio de 2008, en: http://www.lukor.com/not-mun/europa/0807/03202926.htm También: "España y Francia cierran un borrador para un futuro pacto sobre inmigración”, El Mundo, 4 de julio 2008, en http://www.elmundo.es/elmundo/2008/07/03/espana/1215115324.html.

13 "El Parlamento aprueba la Directiva de Retorno de Inmigrantes", Notas de prensa, Sesión Plenaria Inmigración Parlamento Europeo (18 de junio 2008), en http://www.europarl.europa.eu/sides/getDoc.do?language=es\&type=IMPRESS\&reference=20080616IPR31785.

${ }^{14}$ En declaraciones de Trinidad Jiménez y María Teresa Fernández de la Vega sostenían estas opiniones, en: "España vende a Latinoamérica la 'directiva de la vergüenza", Público, 20 de junio 2008, en http://www.publico.es/internacional/128053/espana-vende-a-latinoamerica-la-directiva-de-la-verguenza.
} 
Como lo decíamos en el libro sobre Los flujos migratorios desde Canarias-Madrid, ${ }^{15}$ España al solicitar la entrada en la Comunidad Económica Europea y ser aceptada, había escogido el lugar en el que quería estar, y que como país europeo le correspondía.

De esta forma, con el paso de los años, la Unión Europea y España, como parte integrante de este espacio económico, han ido proyectando leyes sobre la ordenación de los flujos migratorios y ajustes a estas leyes, que nos guste o no, debemos acatar.

A partir del Tratado de Amsterdam, en mayo de 1999, la política de inmigración fue de competencia comunitaria, por ello es muy difícil desvincular la acción de los gobiernos de nuestro país de las instrucciones que vengan desde Bruselas.

En una revisión amable de la situación creada por la inmigración y por la falta de previsión de la misma, podemos ver que de una visión aperturista de la situación europea a la entrada de inmigración de terceros países, se ha ido pasando a un grado de vigilancia y de ordenamiento de los flujos migratorios, por medio de leyes, normativas, reglamentos, que van convirtiendo a la UE y en su defecto a España, en una gran fortaleza a la cual, muchos aspiran y la que en estos momentos y gracias a la crisis, se esgrime la bandera del control.

En el tratado de Niza, aprobado en diciembre de 2000, se reitera la voluntad de que a partir de 2004 las decisiones relativas a inmigración y asilo fueran adoptadas por mayoría cualificada, perdiéndose el control estatal de las políticas migratorias, una dirección que sería también respaldada por la Convención. ${ }^{16}$ En el Consejo europeo de Laeken, celebrado en diciembre del año siguiente, cuatro meses después de los atentados del 11 de septiembre de 2001, la sociedad occidental estaba sumida en el miedo al terrorismo, debido a esa trágica experiencia.

Progresivamente las normativas de la UE han ido en la dirección securitaria del espacio Schengen, para garantizar la seguridad interior y exterior del mismo, y para alentar a la inmigración legal en contra de los flujos incontrolados de ilegales.

Hoy mismo en España, el nuevo reglamento de la ley de extranjería, aprobado en abril de este año 2011, es una clara muestra del peso de las normativas de la UE, en materia de inmigración, que se han ido promoviendo desde el tratado de Amsterdam, para controlar los flujos migratorios y tener un denominador común, entre los 27 , a la hora de administrar correctamente los flujos migratorios hacia la UE.

En un espacio común, como es el espacio Schengen, si no se habla con una sola voz, nos vemos abocados a espectáculos tan poco gratificantes como el sucedido en plena crisis de los países del norte de África, entre dos miembros de la UE, como Francia e Italia, rechazando a la ingente cantidad de migración llegada a las costas italianas, procedente de esos países norteafricanos, y no sólo eso, sino alentando a cerrar las fronteras interiores, en un claro gesto de insolidaridad entre los países europeos, que han apostado por la defensa de un espacio común, en democracia y en paz.

De ahí la puesta en marcha en 2008, del pacto común de inmigración, que se llevó a cabo durante la presidencia con el apoyo de los representantes españoles en Bruselas. Incluso el propio presidente Rodríguez Zapatero, llegó a afirmar que la aprobación del pacto común de inmigración, representaba un avance progresista, afirmando que, a medida que hagamos

\footnotetext{
15 "Flujos migratorios hacia Canarias-Madrid", op. cit., nota 8.

${ }^{16}$ Tandonnet, M. (2003): Migration: la nouvelle vague, París, L’Harmattan, p. 175.
} 
política común, la tendencia será (dar) más garantías. Para concluir diciendo que "cuando comunitarizamos políticas y mucho más si afectan a derechos individuales, se producen avances". ${ }^{17}$

\section{Descenso de la Inmigración}

Entre el año 2006 y el 2010 la llegada de inmigrantes por las fronteras españolas ha conocido un progresivo descenso. Descenso que ha tenido que ver con la serie de acuerdos que el gobierno español ha estado firmando con la mayor parte de los países de África occidental, englobados dentro del primero y segundo Plan África. En segundo lugar, la crisis ha venido a "golpear" directamente a la inmigración. La vuelta a sus países de origen de muchos de estos trabajadores, ha servido de revulsivo a otros, para no salir a buscar trabajo en España. También la actuación del FRONTEX tiene mucho que ver con la disminución de inmigrantes en las costas españolas, cuyos flujos se han ido moviendo con dirección a Italia y Grecia.

Según el ministro del Interior, Alfredo Pérez Rubalcaba, el descenso registrado en las llegadas de ilegales al territorio español entre 2006 y 2009 fue de 32\%, mientras que en el caso de las islas Canarias representó un 92\%. Incluso en este mismo año 2010, sólo llegaron tres pateras y un cayuco a las islas, con quince personas a bordo, frente a las 2.284 , que arribaron en 2009, o las 9.284 que lo hicieron en 2008. ${ }^{18}$ Respecto a Marruecos, se sabe que la UE está dispuesta a dar visados a este país con la condición de que admita clandestinos.

En este mismo año 2009, en el mes de diciembre, entró en vigor la reforma de la Ley de Extranjería 4/2000 y lo que más ha llamado la atención de la misma es la aceleración con que se han efectuado "redadas" dirigidas al colectivo de la inmigración, con el objetivo de intimidar. Según las denuncias de diversos colectivos de asociaciones de inmigrantes, como ONGs y también la propia policía, se produce una acelerada aplicación de la Ley de Extranjería 02/2009, cuya interpretación por parte de la policía, se traduce en detenciones, reclamación de documentación y en tramitar con rapidez expedientes de expulsión.

Son 141 asociaciones en defensa de los Derechos Humanos y colectivos de inmigrantes los que han denunciado ante el Defensor del Pueblo y ante el Ministerio del Interior, estas prácticas abusivas y la "ilegalidad" de la Circular "secreta" 1/2010 de la Comisaría de Extranjería y Fronteras, que entre otras cuestiones insta a la policía a realizar detenciones preventivas, de inmigrantes sin papeles y en la que ordena a ventilar a la "mayor brevedad y en el tiempo mínimo imprescindible y por el procedimiento preferente, la expulsión de irregulares, interceptados en la vía pública”. En un año y sólo en el territorio de la Comunidad de Madrid se practicaron 445.000 detenciones preventivas, según las cifras del SUP. ${ }^{19}$

Con la Presidencia sueca se presenta el Plan Estocolmo que sustituye al Programa de la Haya. El Programa Estocolmo especifica los marcos de cooperación en la UE en justicia y

\footnotetext{
17 “Zapatero a examen internacional”, Entrevista El País, 29 de junio de 2008, en http://www.elpais.com.

18 "Conferencia pronunciada por el ministro del Interior, Alfredo Pérez Rubalcaba", Varsovia (25 de mayo de 2010); "Rubalcaba cree que FRONTEX necesita más datos sobre las mafias de la inmigración”, La Información, 25 de mayo de 2010, en: http://noticias.lainformacion.com/policia-y-justicia/criminalidad/rubalcaba-cree-quefrontex-necesita-mas-datos-sobre-las-mafias-de-la-inmigracion_rzRUW5vj9fBGqB0pEYSnM3/.

19 "Los controles policiales en la vía pública dirigidos a la identificación y detención de personas migrantes irregulares", Estudio elaborado por MUGAK, Centro de Estudios y Documentación sobre racismo y xenofobia de SOS Racismo/SOS Arrazakeria (2010), en

http://www.inmigrapenal.com/Areas/Detenciones/Documentos/DOCUMENTACIONEPISODIOS.pdf.
} 
migración para el período 2010-2014. Como punto más importante a destacar se presenta la política de integración, que sólo tiene en cuenta a los inmigrantes legales y en general el Programa Estocolmo tiene una línea de continuidad con las disposiciones llevadas a cabo en materia de inmigración durante la presidencia francesa. ${ }^{20}$

Con la Presidencia española del Consejo de Ministros de la Unión Europea se afianzan las políticas migratorias propuestas desde la presidencia francesa. Se ha distinguido por llevar a cabo el refuerzo de la política común de inmigración de acuerdo con lo propuesto en el Programa de Estocolmo, adoptando una estrategia común a fin de administrar mejor las fronteras de la UE y satisfacer las necesidades del mercado de trabajo, así como la necesidad de cooperación con los países de origen de la inmigración. Por tanto, para nosotros representa una continuidad con las presidencias que le han precedido, especialmente con la francesa, consolidando la política securitaria. El tema estrella de la Presidencia española 2010 fue el Plan de Acción sobre los Menores No Acompañados o MENAS. Tema complejo y delicado, en el que la presidencia ha conseguido la implicación de los 27 países para encauzar este asunto. El plan refleja no obstante, "la fijación en el retorno de los menores, como solución que redunda en el interés superior del menor". Las repatriaciones conllevan muchos riesgos y los niños son las víctimas más vulnerables. La vigilancia y el seguimiento son imprescindibles por parte de los gobiernos europeos, si no hay más remedio que repatriar. En el caso de los menores se podrían dar muchas otras oportunidades para su incorporación en nuestras sociedades, que seguramente redundaría en beneficio de ellos y nuestro.

La Unión Europea corre el riesgo, no sólo de ir avanzando su frontera hacia el sur del continente, hoy "contestada por las revueltas norteafricanas", con un futuro incierto ante la solución de estas "revueltas" así como de la solución a la actual crisis económica. La repatriación de los inmigrantes clandestinos, en función de los acuerdos con terceros países, contribuirá al aumento de las "bolsas de inmigración" en países en donde se suele convivir con las mafias del narcotráfico y de los traficantes de esclavos. ${ }^{21}$

En el año actual, en el mes de abril de 2011, se acaba de aprobar el reglamento de la ley de extranjería de diciembre de 2009.

Entre los objetivos principales de esta disposición están, “ordenar los flujos migratorios laborales, promocionar la cultura de la regularidad, fomentar la integración y la igualdad de derechos y deberes, fortaleciendo la cohesión social en un contexto de diversidad cultural, desde la lógica de la igualdad de derechos y deberes", 22 que la Ley de Extranjería de 2009 se desarrolle para luchar contra la cultura de la irregularidad documental, como algo socialmente aceptado por todos los inmigrantes, sean estos legales e ilegales, y también dotar de mayor protección a los extranjeros que se encuentren integrados en España. Por su parte el ministerio de Trabajo e Inmigración ha buscado con este reglamento una mayor protección a los extranjeros en situación de vulnerabilidad, como es el caso de los MENAS o menores extranjeros no acompañados y el de mujeres maltratadas.

\footnotetext{
20 "Una Europa abierta y segura que sirva y proteja al ciudadano", Programa Estocolmo, Diario Oficial de La Unión Europea (4 de mayo 2010) en http://eur-lex.europa.eu/LexUriServ/LexUriServ.do?uri=OJ:C:2010:115:0001:0038:es:PDF.

21 Véase: Brachet, Julien (2009): Migrations transhahariennes. Vers un desert cosmopolite et morcelé, Broissieux, Éditions du Croquant.

${ }^{22}$ Boletín Oficial del Estado n ${ }^{\circ} 103$, Sección 1 (30 de abril 2011), p. 43832, en

http://www.boe.es/boe/dias/2011/04/30/pdfs/BOE-A-2011-7703.pdf.
} 
Hasta el mes de abril el Programa Estocolmo era una declaración de intenciones, a partir de la aprobación del Reglamento de la Ley Orgánica 4/2000, sobre Derechos y Libertades de los Extranjeros en España y su integración social, se pone en marcha todo lo que se recomienda en el Programa Estocolmo.

Desde una perspectiva material, las novedades del Reglamento responden sobre todo a la voluntad de consolidar un modelo basado en la regularidad y vinculado al mercado de trabajo.

El nuevo Reglamento pretende optimizar en este nuevo contexto los principios de la política migratoria reconocidos por primera vez a través de la Ley Orgánica 2/2009, de 11 de diciembre, principios entre los que se encuentran la ordenación de los flujos migratorios laborales de acuerdo con la situación nacional de empleo, la integración social de las personas inmigrantes, la lucha contra la inmigración irregular y las relaciones con terceros países en materia de inmigración.

Cabe destacar entre las novedades la figura del "arraigo familiar" que se suma a las ya existentes de arraigo social y arraigo laboral.

Según se recoge en el artículo 122 del Reglamento, el arraigo familiar, permite conceder al Gobierno una autorización de residencia de carácter temporal "cuando se trate de padre o madre de un menor de nacionalidad española, siempre que el menor esté a cargo de y conviva con el progenitor que solicite la autorización". Y, también, "cuando se trate de hijos de padre o madre que hubieran sido originariamente españoles. El Defensor del Pueblo ha recomendado en sucesivas peticiones al Gobierno que cambiara la ley en este sentido. De esta forma se tiene en cuenta a un colectivo que tenía todos los caracteres de vulnerabilidad, al correr el riesgo de quedarse solos sin sus progenitores, en caso de que estos fueran expulsados del territorio español y también se les facilitan las ayudas que de otra forma no podrían solicitar.

Por su parte, la secretaria de Estado para la Inmigración Anna Terrón ha recordado que "el arraigo es algo excepcional y debe ir disminuyendo cada vez más por razones de contexto y realidad". 23

Se precisa que las mujeres embarazadas que llegan en patera a España, no se beneficiarán de esta figura jurídica.

Otra novedad que se estipula en el documento es la de que los inmigrantes que se acojan a los planes de retorno voluntario a su país, no perderán la antigüedad de sus permisos de residencia y trabajo en España, de modo que se fomente la "inmigración circular", es decir, que cuando la situación económica en España mejore y lo requiera, puedan volver para trabajar nuevamente. Medida con buena intención, pero sin garantía ninguna de que se pueda llevar a cabo.

Por otra parte, existen apartados "polémicos", pero que siguen la pauta trazada por las normativas de la UE. Entre ellos están, por ejemplo, el internamiento máximo de los ilegales, que aumenta de 40 a 60 días.

\footnotetext{
23 "El gobierno regularizará a los "sin papeles" con hijos españoles, menores de edad", El Mundo, 9 febrero 2011), en http://www.elmundo.es/elmundo/2011/02/08/espana/1297170766.html.
} 
La reagrupación familiar que tiene en cuenta al conyugue, los hijos de uno de los conyugues y demostrar que se tiene una renta mínima para su sostenimiento. Renta en base al IPREM. $^{24}$ Los mayores de 65 años, también están incluidos en la reagrupación familiar, aunque se pueden estudiar casos excepcionales.

Se tiene en cuenta por primera vez, la figura de "pareja de hecho", para poder ser reagrupadas. El permiso laboral, que podrá ser concedido a los familiares reagrupados con edad laboral. Las mujeres que sufran "maltrato" y denuncien la agresión y obtengan una orden de protección, podrán obtener una autorización provisional de residencia y trabajo hasta que se dicte sentencia.

En cuanto a las víctimas de la trata de mujeres, si colaboran con las autoridades, podrán obtener una autorización de residencia.

Para acabar con la cultura de la ilegalidad se sanciona a los empresarios que contraten a inmigrantes "sin papeles", quienes deberán pagar la repatriación de estos.

Es interesante destacar que en las contrataciones, se tendrán en cuenta a los inmigrantes legales que ya se encuentren en territorio español. Medida que ahorra gastos en desplazamientos y en adaptación.

Y en consonancia con la UE se mejora la intercomunicación entre Administraciones y Comunidades Autónomas, en base a las nuevas tecnologías.

\section{Conclusión}

España, en estos 10 últimos años ha tenido, a nuestro juicio, una política migratoria con una línea de continuidad, marcada por el control de la inmigración y la persecución a la inmigración ilegal, como una clara divisa de su pertenencia al espacio europeo Schengen.

A medida que han ido pasando los años, las normativas europeas, desde el programa de la Haya al Programa de Estocolmo, han marcado la pauta a seguir por los 27 en el tema de la inmigración, y muy especialmente tomado en cuenta por países como España, que no solo es frontera exterior con el continente africano sino también con el hispanoamericano, además del precedente que marcó la petición de ayuda a la UE por parte del gobierno del presidente Zapatero, para controlar los flujos migratorios procedentes de África subsahariana en el año 2006, con la denominada "crisis de los cayucos".

El paraguas de la UE le ha servido a los gobiernos españoles para acogerse a todas las normativas y participar activamente en su redacción y presentarlas como necesarias, a la hora de tener que dar explicaciones a la ciudadanía, que por otra parte, apenas si se hace mención de ello en los diversos discursos que se emplean para hablar sobre la situación de España en la UE en relación a la inmigración.

Como un ejemplo de ello, está la última aprobación del reglamento de extranjería, en abril de 2011, para poner en marcha la ley de extranjería de 2009, en cuyo texto se explica que todo se realiza para actualizar comportamientos que debe regir la cuestión migratoria,

\footnotetext{
${ }^{24}$ Indicador Público de Renta de Efectos Múltiples.
} 
pero sin aclarar que se pone en marcha el Programa Estocolmo que abarca el período 20102014, como se recoge seguidamente:

..."de acuerdo con el mandato legal y con la política europea de inmigración, se ha efectuado el desarrollo reglamentario de determinadas Directivas europeas, cuya transposición se efectuaba en la propia reforma de la Ley Orgánica. Estas Directivas, en algún caso ya incorporadas a nuestro ordenamiento jurídico, configuran un marco normativo europeo común en materia de inmigración en el que España participa plenamente".

Se introduce también la tarjeta azul, sin nombrarla, para la contratación de personal de alta cualificación. "La atracción de investigadores y personal altamente cualificado, así como la regulación de los flujos laborales que afectan a actividades que concurren España, razones de interés económico, social o laboral, ..., medidas que favorezcan la competitividad de la economía española y la internacionalización de las empresas. ${ }^{25}$

Queda claro, que interesa fomentar el retorno de la inmigración sin cualificar y atraer a la cualificada.

No sabemos qué nos depare el futuro, lo que queda claro es que el avance en las políticas de seguridad en la UE sigue una línea continua y tiene un efecto inmediato en España, en clara armonía con lo que se legisla desde Bruselas, adaptando la legislación nacional en concordancia con la defensa de un espacio de libertad y seguridad para los europeos.

\footnotetext{
${ }^{25}$ BOE. 30 de abril de 2011. pag. 43832. En: http://www.boe.es/boe/dias/2011/04/30/pdfs/BOE-A-20117703.pdf
} 